\title{
Simulation in Residency Training: A Review
}

\author{
Michael T. Flannery, Sharon Zahorsky \\ Department of Internal Medicine, University of South Florida Morsani College of Medicine, Tampa, USA \\ Email: mflann5555@aol.com szahorsk@health.usf.edu
}

Received December $3^{\text {rd }}$, 2013; revised January $3^{\text {rd }}$, 2014; accepted January $10^{\text {th }}, 2014$

\begin{abstract}
Copyright (C) 2014 Michael T. Flannery, Sharon Zahorsky. This is an open access article distributed under the Creative Commons Attribution License, which permits unrestricted use, distribution, and reproduction in any medium, provided the original work is properly cited. In accordance of the Creative Commons Attribution License all Copyrights (C) 2014 are reserved for SCIRP and the owner of the intellectual property Michael T. Flannery, Sharon Zahorsky. All Copyright @ 2014 are guarded by law and by SCIRP as a guardian.
\end{abstract}

Background: Simulation suddenly came into the limelight of regulation a few years ago when the Accreditation Council on Graduate Medical Education (ACGME) recommended simulation training without specifics. That left internal medicine program directors confused as they tried to figure out what was best for their residents. Summary: The author's review discusses the many issues and unanswered questions regarding simulation training. It appears clear to this faculty member that residents enjoy the additional training to make them more comfortable doing procedures related to their training. A few studies mention longevity in retention of skills learned over time and very few discuss the numbers of procedures to attain competency and outcome improvements if they occur. Conclusion: This leaves several areas that need further study on the effects of simulation training in residency and meeting the needs of post-graduate descriptions via surveys following training. What kind of procedures and clinical scenarios (codes, medical dilemmas, ethical/communication issues), how often/how many, timing and appropriate measurements especially if focusing on improved patient outcomes. This narrative summary utilized a review focusing on simulation, internal medicine and various simulation outcomes.

Keywords: Simulation; Internal Medicine; Education

\section{Simulation in Residency Training: A Review}

Simulation has been defined as imitation or representation of a process used in a controlled or monitored situation for the purpose of training (Gabbai, 2001). Simulation has been utilized for up to seventy years in the aerospace industry (Gabbai, 2001). The Accreditation Council on Graduate Medical Education (ACGME) had a statement that appeared just a few years ago that said "simulation should be utilized in the education of residents". Of course, this was a generalized statement without specifics which sent program directors into a quandary. The goals were thought to be to increase resident preparation for various common medical procedures. There were several issues to be determined including resident mastery and satisfaction, length of retaining knowledge and skills and outcome improvement to decrease patient mistakes and injuries related to the old see one, do one and teach one methodology. A literature search was undertaken with the focus on various forms of simulation training, competency and outcomes predominately in internal medicine residency programs. The results of which are described below.

\section{Resident Simulation/Outcomes}

The utilization of simulation has been studied in various procedures including central venous catheter insertion (Barsuk et al., 2009), lumbar puncture (White et al., 2012), cardiac arrest (Healy et al., 2010) and emergency airway management (Fraser et al., 2009). Other simulation studies reviewed long term retention and transfer of abilities (Summerhill et al., 2007), disaster preparedness (Barsuk et al., 2009), reduction of bloodstream infections with invasive procedures (Bong et al., 2010), physiologic stress during simulation and effects of feedback and debriefing (Hayes et al., 2007). Defining which procedures need to be mastered during residency usually can be found in the program's ACGME rules and regulations. However, this typically generates a list of procedures with a possible numeric attestation of how many need to be done to be competent. Competency cannot be assumed and is not equally attained by various residents. One might assume that patients would no doubt be more comfortable knowing that there team of physicians are well trained in the particular procedure they are about to undergo.

One study demonstrated that residents feel unprepared and unsupervised as leaders of cardiac arrest teams. Only 52\% felt prepared to lead a cardiac arrest team with $55 \%$ worrying that they made errors (Brim et al., 2010). Another study, regarding studenttraining on simulation during a medical clerkship, demonstrated that during a 6 year period 327 Harvard students participated in a simulator based teaching experience on the principles on myocardial infarction (MI), in addition to their 12 week medicine clerkship curriculum. Ninety-nine percent of students found the experience valuable with $>69 \%$ requesting multiple sessions. When compared with real life experiences, $78 \%$ had a didactic session on MI and $47 \%$ had an exposure to a patient with an MI (Sharpe et al., 2010). Another consideration is stress levels during simulation versus traditional teaching. One study reviewed 27 gastroenterology physicians who 
were randomized to simulation based training (SBT) versus traditional based training (TBT) involving tutorial based interactive training. Physicians exposed to SBT experienced greater increased in heart rate and salivary cortisol when compared with TBT (Hayes et al., 2007). The effects of such physiologic stimulation to SBT on cognition and retention need to be studied further.

One of the major changes in the ACGME rules and regulations in the past 10 years have been resident work hours. The effect of excessive work hours and fatigue has also been studied when reviewed in relevance to simulation training. Residents undergoing a 26 hour work shift were studied at four different points on 8 different simulated rhythm disturbances. While improvements were made between points one and two there was significant increase in errors from 0.92 to 1.58 from the first to fourth sessions (Gordon et al., 2010). Another study reviewed simulator scores after an extended shift of 24-30 hours compared to a rested state. Again scores were significantly lower and consistent with prior real time hospital studies using the same shift schedule (Barsuk, 2011).

Another collateral effect, that was unexpected but beneficial ,was the effect of SBT for central venous insertion in senior residents on the improvement of junior residents' skills/scores (Barsuk et al., 2009). The mastery of the procedure was maintained for a least one year as noted in many other studies. One could easily surmise that senior residents would take time to educate their junior residents on proper technique which would improve scores. However, this in no way should replace SBT for junior members as there is great variation amongst residents even when utilizing the old way of see one, do one and teach one which is not appropriate to high risk, low frequency events such as cardiac or respiratory arrest.

One of the most commonly studied internal medicine procedures in the SBT setting is central venous catheter (CVC) insertion. This common to many of the core residencies and, therefore, is not a surprise that it was studied extensively. In one study set in the MICU, no residents met a passing score at baseline for CVC insertion. Residents undergoing simulated CVC insertion demonstrated more self-confidence and fewer passes for CVC insertion (Smith et al., 2010).A similar study, CVC procedural skills improved but decayed to the control group after a period of time. The was thought secondary to the low number of CVC insertions during that rotation averaging 1.7CVC's over a 3 - 4 week period of time (Evans et al., 2010). Another study randomized, controlled, single blinded study of first and second year residents reviewed 495 CVC insertions by 115 residents over 21 months. SBT was associated with significance at first time successful insertion of the CVC (Barsuk et al., 2010). Finally, another CVC insertion studied focused on long term retention of skills. Whereas $100 \%$ of residents passed simulation training initially, there was some decay with $82-87 \%$ passing simulation or post testing scores at one year. The authors suggested that the residents should have periodic testing and perhaps a refresher course (Cohen et al., 2010). If simulation can improve CVC procedural skills, how about the outcomes, such as infection rates? This was reviewed in 2010 looking at catheter related bloodstream infections (CRBI) after simulation training in the MICU. Approximately 9.95 CRBI's were prevented among MICU patients in the year after the simulation intervention. The cost of the education intervention was 112 thousand dollars and compared with the cost of treating the CRBI for 2 weeks resulted in a net annual savings greater than 700 thousand dollars. Compared to other ICU loca- tions, in that hospital system, in which no intervention occurred, there was no change in CRBI's (Mayo et al.,2004).

Simulation of airway emergencies is particularly important in reviewing training responses to high risk but low frequency events such codes requiring airway placement. One study randomized interns after advanced cardiac life support training to immediate simulation or delayed simulation. Those receiving immediate intervention showed significant improvement immediately after intervention and at 4 weeks. The improvement appeared to be transferable to the patient's bedside via attending evaluation. The delayed group showed no improvement (Mayo, 2004). The latter group received their testing at a later time to attempt to exclude the possibility that the testing itself was not a demotivating factor. The initial group of interns received a simulation intervention which was repeated at 6 weeks and then they were monitored throughout the following year by attending's. All starting interns had poor scores that improved significantly after the intervention and was maintained on retesting and during patient events throughout the year (Rosenthal et al., 2006). Another study, reviewed airway management skills of senior residents. They were randomized to the SBT (simulation based treatment) versus TBT (traditional based treatment). TBT was random experiences of residents during code situations. The SBT group performed better than the TBT group in 8 of the 11 steps of a respiratory arrest protocol. Therefore, traditional training over 2 years was insufficient to achieve proficiency without SBT. This is particular concerning as they may have had several unit experiences and been the team leader on codes for up to one year previously (Kory et al., 2007).

As mentioned previously, when it comes to cardiac arrest and codes residents feel unprepared but also $73 \%$ of residents reported that they did not receive staff supervision during weekdays and that number increases to $96 \%$ for weekends (Brim et al., 2002). In one of the first ACLS (Advanced Cardiac Life Support) longitudinal studies, small group simulation on traditional ACLS via eight hours on the simulator assessing six simulated scenario's. The residents were followed up for 14 months and showed no significant decay in their ACLS skills. (Wayne et al., 2008) Of course, one limitation is the low frequency of events over such a time period which depends on unit assignment and night call for the code team backup. One study reviewed the comfort level of senior internal medicine residents with in-hospital resuscitation. There were five different knowledge sets reviewed including cardiac rhythm assessment, delivery bad news, and discussion of code status, widecomplex tachycardia and bradycardia management. In addition, skills sets were included defibrillation, airway management, central venous access etc. Only $28 \%$ of residents felt prepared before the course and after the course $45 \%$ of participants reported using the knowledge and skills taught with a significant mean improvement in confidence (Healy et al., 2010). Another simulation based education on adherence to American Heart Association standards showed significant adherence with an odds ratio of 7.1 on SBT versus TBT in third year residents. SBT residents were not followed longitudinally (Wayne et al., 2008). In a cardiac arrest debriefing of the weeks prior cardiopulmonary resuscitation (CPR) events led to significant CPR improvements but no change in survival at discharge (Edelson et al., 2008). Simulator based cardiac exam competence combined with checklists also improved cardiac exam performance by residents in internal medicine (Hatala et al., 2009). A simulation evaluation of cardiac fellow performance on interven- 
tional cardiac procedures was able to identify weak performers beyond that of written examination. This allowed immediate feedback in potentially difficult situations and could be integrated into the written curriculum (Lipner et al., 2010).

Internal medicine residency programs at centers with emergency medicine residencies often lack enough lumbar puncture (LP) experience. This is due to the fact that many of the emergency room residents perform the procedure before the medicine residents arrive to evaluate the patient. Therefore, this is another area to focus on for simulation and subsequent patient skills. One study evaluated simulated trained internal medicine interns against traditionally trained neurologists. The interns nearly doubled their scores and outperformed the trained neurologists (Barsuk et al., 2012). One more recent study found that only $29 \%$ of interns performed an LP (lumbar puncture) in medical school and only 9\% have done more than 5 LP's (Gaies, 2007). Another study, looking at pediatric interns, found a $12 \%$ improvement on pre-test versus post-test scores. Utilizing a checklist after the intervention interns averaged 9.7 of the 11 checklist points with the number of averaged attempts at 1.4. Forty-eight percent of the interns performed the procedure correctly. Survey data demonstrated that confidence improved with the number of procedures undertaken (White, 2010).

Another area fearsome to residents is the intensive care experiences where a wide variety of procedures may need to be undertaken during the rotation. Studies on simulation based education in the medical intensive care units demonstrated that SBT interns scored higher on bedside skills assessment when compared with TBT interns and such skills were transferable to actual patient care (Schroedl et al., 2012). SBT resident's also demonstrated higher levels of satisfaction with their SBT. Other studies showed that debriefing sessions utilizing a checklist allowed evaluation of resident performance in critical care standards (Clay et al., 2007; Lighthall et al., 2003). Similar to other studies residents improved their short term skills, improved confidence, decreased errors and had higher levels of satisfaction. The areas that need further study include longer term effects and outcome measures that demonstrate improved morbidity and mortality evidence.

\section{Number of Procedures Needed for Competency}

Another area to evaluate is how many procedures a resident needs to do in order to achieve competence. Traditionally, utilizing the ABIM procedure books it was stated that 3 - 5 procedures need to be completed to achieve competency for the most common procedures. Most program directors would no doubt agree that such numbers are inadequate across the board. A number of studies have indicated that to achieve a comfortable or very comfortable level of confidence roughly $65 \%$ of residents achieve this level having done 6 - 10 procedures. Supervision and repetition were critical components of comfort. Procedures requiring higher numbers to achieve such comfort were central venous access and endotracheal intubation (Huang et al., 2006; Smith et al., 2004). Comfort levels were consistent with experience with post-graduate year (PGY) one at 34\% comfortable handling procedures to $71 \%$ for PGY 2 and $61 \%$ for PGY 3. The decrease in the PGY3 year certainly may be due to the predominance of elective rotations out of the limelight of the intensive care units. To improve comfort and, hopefully, competency levels one program initiated an inpatient proceduralmedical service with a designed curriculum and mechanisms of evaluation (Smith et al., 2004). One paper described four stages of competency development for procedures from knowledge to exposure to skill acquisition and finally, competence usually determined via checklists or simulation training (Manthey et al., 2012).

Current policies and procedure requirements for the American Board of Internal Medicine (ABIM) indicate a minimum of 5 procedures the resident should perform safely and competently which included; advanced cardiac life support, drawing of venous and arterial blood, Pap smear and endocervical cultures and placing a peripheral venous line. It is certainly reasonable to believe that the drawing of venous and arterial blood and the placement of a venous access is something that can be competently achieved in medical school. For other common procedures an internist should be able to know, understand and explain the indications, complication, sterile technique, pain management, sterile handling, interpretation of results, knowledge to obtain informed consent (ABIM, 2013). There is no mention of how many procedures need to done to achieve competency. Many recognize 3 components to achieving competency which include; knowledge, differentiation between normal and abnormal findings and testing such as simulation (Norris et al., 2007).

Determine the number of simulation procedures will vary to some degree depending on what specialty a resident may enter. OF course all internal medicine residents should experiences a core of procedures as specified by the ABIM and ACGME. Respondents to a 2004 survey indicated EKG (Electrocardiogram) interpretation (200) as number one procedure completed followed by microscopic examination of the urine (100). Other high areas ( $>50$ median number of procedures in the past year) included CXR (Chest X-ray) examination (90), cryosurgical removal of skin lesions (50), esophagogastroduodenoscopy (50), colonoscopy (87) and treadmill exercise testing (50). Most other procedures were 10 or less over the past year including CVC placement (10), thoracentesis (3), paracentesis (2) (Wigton et al., 2007). The survey though 9 years old indicates that surveying post-graduates from your program is an important process to identify any procedural needs that went untaught or trained during their residency.

\section{Summary}

In summary, every program with the support of their graduate medical office must determine which and how many procedures should be performed at specific times to achieve competency per the individual resident. Clearly simulation improves immediate confidence and performance across a wide variety of procedures in different situations. Assigning a base number of procedures that need to be completed as the residents finish their PGY1 year and PGY3 year for internal medicine may be necessary. However, they are very likely to be higher than the ABIM has listed as expectations of 3 - 5 procedures. Given the fact that much of the evidence demonstrates decay in simulation skills repetition at various points during residency will be needed across a broad number of clinical scenarios. These may include codes, medical emergencies and ethicaldilemmas. This is also an opportunity to invest in joint ventures with the hospital so that necessary personnel such as Anesthesia, nursing and pharmacy participate in the simulation and debriefing process. 
Another area for investigation is monitoring outcome measurements which should be undertaken as a part of the quality review process. This would be applicable not only to the quality of the simulation training but the study of the evidence that may support improved patient outcomes. It would seem reasonable to this author that some basic ACLS and medical emergencies are on a continuum from the student's clinical UME to their GME experiences. These basic skills can then be further reinforced during their residency training. Certain procedures, such as central venous line placement, thoracentesis, paracentesis, arthrocentesis and lumbar puncture can be practiced in the simulation lab at the beginning of their PGY1 year and then repeated at the end of the year before approval to do such procedures independently as a PGY2 supervisor. This would be accomplished via faculty participation at key points and during the debriefing process. In between, ongoing checklists can be utilized on real patient procedures to insure procedures that are done correctly and minimize error and stress. Future studies are necessary to determine how many procedures need to be accomplished for each given resident with minimal numbers set between 6 - 10 based on prior studies before advancing to the PGY2 year and perhaps higher prior to graduation. Obviously, some residents may need additional training in specific clinical dilemmas or procedures so one number does not equal competency for all.

\section{REFERENCES}

American Board of Internal Medicine. (2013). Policies and procedures for certification.

Barsuk, J. H., Cohen, E. R., Feinglass, J., \& William, C. (2009). Use of simulation-based education to reduce catheter-related bloodstream infections. JAMA Internal Medicine, 109, 1420-1423. http://dx.doi.org/10.1001/archinternmed.2009.215

Barsuk, J. H., Cohen, E. R., Feinglass, J. McGaghie, W. C., \& Wayne, D. B. (2011). Unexpected collateral effects of simulation-based medical education. Academic Medicine, 86, 1513-1517. http://dx.doi.org/10.1097/ACM.0b013e318234c493

Barsuk, J. H., McGaghie, W. C., Cohen, E. R., Balachandran, J. S., \& Wayne, D. B. (2009). Use of simulation-based mastery learning to improve the quality of central venous catheter placement in the medical intensive unit. Journal of Hospital Medicine, 4, 397-403. http://dx.doi.org/10.1002/jhm.468

Barsuk, J. H., Cohen, E. R., McGaghie, W. C., \& Wayne, D. B. (2010). Long term retention of central venous catheter insertion skills after simulation-based mastery learning. Academic Medicine, 85, S9-S12. http://dx.doi.org/10.1097/ACM.0b013e3181ed436c

Barsuk, J. H., Cohen, E. R., Caprio, T., McGaghie, W. C., Simuni, T., \& Wayne, D. B. (2012). Simulation-based education with mastery learning improves residents' lumbar puncture skills. Neurology, 79, 132-137. http://dx.doi.org/10.1212/WNL.0b013e31825dd39d

Bong, C. L., Lightdale, J. R., Fredette, M. E., \& Weinstock, P. (2010). Effects of simulation versus traditional tutorial-based training on physiologic stress levels among clinicians: A pilot study. Simulation in Healthcare, 5, 272-278.

Brim, N. M., Venkatan, S. K., Gordon, J. A., \& Alexander, E. K. (2010) Long-term educational impact of a simulator curriculum on medical student education in an internal medicine clerkship. Simulation in Healthcare, 5, 75-81.

Clay, A. S., Que, L., Petrusa, E. R., Sebastian, M., \& Govert, J. (2007). Debriefing in the intensive care unit: A feedback tool to facilitate bedside teaching. Critical Care Medicine, 35, 738-754. http://dx.doi.org/10.1097/01.CCM.0000257329.22025.18

Cohen, E. R., Feinglass, J., Barsuk, J. H., Barnard, C., O’Donnell, A., McGaghie, W. C., \& Wayne, D. B. (2010). Cost savings from reduced catheter-related bloodstream infection after simulation-based education for residents in a medical intensive care unit. Simulation in Healthcare, 5, 98-102.

http://dx.doi.org/10.1097/SIH.0b013e3181bc8304

Edelson, D. P., Litzinger, B., Arora, V., Walsh, D., Kim, S., Lauderdale, D. S. et al. (2008). Improving in-hospital cardiac arrest process and outcomes with performance debriefing. JAMA Internal Medicine, 168, 1063-1069. http://dx.doi.org/10.1001/archinte.168.10.1063

Evans, L. V., Dodge, K. L., Shah, T. D., Kaplan, L. J., Siegel, M. D., Moore, C. L. et al. (2010). Simulation training in central venous catheter insertion: improved performance in clinical practice. Academic Medicine, 85, 1462-1469. http://dx.doi.org/10.1097/ACM.0b013e3181eac9a3

Fraser, K., Peets, A., Walker, I., Tworek, J., Paget, M., Wright, B. et al. (2009). The effect of simulator training on clinical skills acquisition, retention and transfer. Medical Education, 43, 784-789. http://dx.doi.org/10.1111/j.1365-2923.2009.03412.x

Gabbai, J. (2001). The art of flight simulation. Emergent Systems, Management and AerospaceTraining, 1-16.

Gaies, M. G. (2007). Assessing procedural skills training in pediatric residency programs. Pediatrics, 120, 715-722. http://dx.doi.org/10.1542/peds.2007-0325

Gordon, J. A., Alexander, E. K., Lockley, S. W., Flynn-Evans, E., Venkatan, S. K., Landriqan, C. P. et al. (2010) Does simulator-based clinical performance correlate with actual hospital behavior? The effect of extended work hours on patient care provided by medical interns. Academic Medicine, 85, 1583-1588. http://dx.doi.org/10.1097/ACM.0b013e3181f073f0

Hatala, R., Scalese, R. J., Gary, C., Baccus, M., Kassen, B., \& Issenberg, C. B. (2009). Development and validation of a cardiac findingchecklist for use with simulator-based assessments of cardiac physical examination competence. Simulation in Healthcare, 4, 1721. http://dx.doi.org/10.1097/ACM.0b013e3181f073f0

Hayes, C. W., Rhee, A., Detsky, M. E., Leblanc, V. R., \& Wax, R. S. (2007). Residents feel unprepared and unsupervised as Leaders of Cardiac arrest teams in Teaching Hospitals: A survey of Internal Medicine Residents. Critical Care Medicine, 35, 1668-1672. http://dx.doi.org/10.1097/01.CCM.0000268059.42429.39

Healy, A., Sherbino, J., Fan, J, Mensour, M., Upadhye, S., \& Wasi, P. (2010). A low-fidelity simulation curriculum addresses needs identified by faculty and improves the comfort level of senior internal medicine resident physicians with inhospital resuscitation. Critical Care Medicine, 38, 1899-1903. http://dx.doi.org/10.1097/CCM.0b013e3181eb3ca9

Huang, G. C., Smith, C. C., Gordon, C. E., Feller-Kopman, D. J., Davis, R. B., Phillips, R. S. et al. (2006). Beyond the comfort zone: Residents assess their comfort performing inpatient medical procedures. American Journal of Medicine, 119, 71.e17-71. e24.

Kory, P. D., Eisen, L. A., Adachi, M., Ribaudo, V. A., Rosenthal, M. E., \& Mayo, P. H. (2007). Initial airway management skills of senior residents. Chest, 132, 1927-1931. http://dx.doi.org/10.1378/chest.07-1554

Lighthall, G. K., Barr, J., Howard, S. K., Gellar, E., Sowb, Y., Bertacini, E. et al. (2003). Use of a fully simulated intensive care unit environment for critical event management training for internal medicine residents. Critical Care Medicine, 31, 2437-2443. http://dx.doi.org/10.1097/01.CCM.0000089645.94121.42

Lipner, R. S., Messenger, J. C., Kangilaski, R., Baim, D. S., Holmes Jr., D. R., Williams, D. O. et al. (2010). A technical and cognitive skills evaluation of performance in interventional cardiology procedures using medical simulation. Simulation in Healthcare, 5, 65-74.

Manthey, D., \& Fitch, M. (2012). Stages of competency for medical procedures. Teaching \& Learning, 9, 317-319.

Mayo, P. H., Hackney, J. E., Mueck. J. T., Ribaudo, V., \& Schneider, R. F. (2004). Achieving house staff competence in emergency airway management: Results of a teaching program using a computerized patient simulator. Critical Care Medicine, 32, 2422-2427. http://dx.doi.org/10.1097/01.CCM.0000147768.42813.A2

Norris, T. E., Cullison, S. W., \& Fihn, S. D. (2007). Teaching procedural skills. Journal of General Internal Medicine, 2, S64-S70.

Rosenthal, M. E., Adachi, M., Ribaudo, V., Mueck, T., Schneider, R. F., 
\& Mayo, P. H. (2006). Achieving houses taff competence in emergency airway management using scenario based simulation training. Chest, 129, 1453-1458.

http://dx.doi.org/10.1097/01.CCM.0000147768.42813.A2

Schroedl, C. J., Corbridge, T. C., Cohen, E. R., Fakhran, S. S., Schimmel, D., McGaghie, W. C. et al . (2012). Use of simulation-based education to improve resident learning and patient care in the medical intensive care unit: A randomized trial. Journal of Critical Care, 27, 219.e7-219.e13.

Sharpe, R., Koval, V., Ronco, J. J., Qakumi, K., Dodek, P., Wong, H. et al. (2010). The impact of prolonged continuous wakefulness on resident clinical performance in the intensive care unit: a patient simulator study. Critical Care Medicine, 38, 766-770.

http://dx.doi.org/10.1097/CCM.0b013e3181cd122a

Smith, C. C., Gordon, C. E., Feller-Kopman, D., Huang, G. C., Weingart, S. N., Davis, R. B. et al. (2004). Creation of an innovative inpatient medical procedure service and method to evaluate house staff competency. Journal of General Internal Medicine, 19, 510-513. http://dx.doi.org/10.1111/j.1525-1497.2004.30161.x

Smith, C. C., Huang, G. C., Newman, L. R., Clardy, P. F., Feller-Kopman, A., Cho, M., Ennacheril, T., \& Schwartzstein, R. M. (2010). Simulation training and its effect on long-term resident performance in central venous catheterization. Simulation in Healthcare, 5, 146-151. http://dx.doi.org/10.1097/SIH.0b013e3181dd9672

Summerhill, E. M., Mathew, M. C., Stipho, S., Artenstein, A. W., Jagminas, L., Russo-Magno, P. M., Potter, S., \& Shapiro, M. J. (2007). A simulation-based biodefense and disaster prepardness curriculum for internal medicine residents. Medical Teacher, 30, e145-e151. http://dx.doi.org/10.1080/01421590802047257

Wayne, D. B., Didwania, A., Feingalss, J., Fudula, M. J., Barsuk, J. H., \& McGaghie, W. C. (2008). Simulation-based education improves quality of care during cardiac arrest team responses at an academic teaching hospital. Chest, 133, 56-61. http://dx.doi.org/10.1378/chest.07-0131

White, M. L., Jones, R., Zinkan, L., \& Tofil, N. M. (2012). Transfer of simulated lumbar puncture training to theclinicalsetting. Pediatric Emergency Care, 28, 1009-1012. http://dx.doi.org/10.1097/PEC.0b013e31826ca96b

Wigton, R. S., \& Alguire, P. (2007). The declining number and variety of procedures done by general internists: A resurvey of members of the American college of physicians. Annals of Internal Medicine, 146, 355-360.

http://dx.doi.org/10.7326/0003-4819-146-5-200703060-00007 